\title{
Massive limb lymphedema as the initial presentation of multiple myeloma: a case report
}

\author{
Chunmei Yang, Liangshun You, Haitao Meng \\ Department of Hematology, The First Affiliated Hospital, College of Medicine, Zhejiang University, Hangzhou, China \\ Correspondence to: Haitao Meng, MD, PhD. Department of Hematology, The First Affiliated Hospital, College of Medicine, Zhejiang University, 79\# \\ Qingchun Road, Hangzhou 310003, China. Email: menghait2004@zju.edu.cn.
}

\begin{abstract}
Multiple myeloma is a malignant neoplasm of plasma cells that primarily causes bone destruction and marrow failure. We report a female patient who presented with limb lymphedema as the first manifestation of multiple myeloma. According to guideline of the International Myeloma Working Group, this patient was diagnosed as symptomatic IgG lambda MM (Durie-Salmon stage II and International System Stage II) based on the detected values of an M-protein in the serum, clonal bone marrow plasma cells $>10 \%$ and anemia. Lymphedema was divided into primary and secondary. The most common secondary factor is malignant tumor, especially breast cancer. We excluded other causes and found no other contributing factors to the patient's massive limb lymphedema apart from multiple myeloma. After one cycle of bortezomibbased chemotherapy, the patient's lymphedema began to resolve and almost completely disappeared after 4 months. As far as we know, this is the first reported case of multiple myeloma patient who developed massive lymphedema. NF- $\kappa \mathrm{B}$ signaling pathway is the main pathogenesis of multiple myeloma, and closely related with the development of lymphedema. More importantly, the symptom of lymphedema relieved after the treatment of NF- $\mathrm{KB}$ inhibitor Bortezomib in this patient. Based on the findings of the present study, as well as those of the literature, we proposed NF- $\kappa \mathrm{B}$ may play an important role in the development of the patient's lymphedema. Further studies are warranted to explain the underlying mechanisms. But this case indicated multiple myeloma may present atypically. We should further examine and clarify the secondary factors of lymphedema, in order to early diagnosis and treatment.
\end{abstract}

Keywords: Lymphedema; multiple myeloma; Bortezomib; NF-кB; case report

Submitted Oct 24, 2020. Accepted for publication Jan 22, 2021.

doi: $10.21037 /$ tcr-20-3143

View this article at: http://dx.doi.org/10.21037/tcr-20-3143

\section{Introduction}

Multiple myeloma is a malignant neoplasm of plasma cells that leading to several symptoms such as lytic bone lesions, anemia, renal disease and hypercalcemia (1). Lymphedema is due to congenital or secondary causes that obstruct the return of lymphatic fluid, leading to local tissue edema. The main symptoms are edema and paresthesia, which can lead to complications such as secondary infection, lymphatic leakage, and skin fibrosis (2). The current study presents a rare case of a 78-year-old woman suffered from multiple myeloma, presenting with the initial manifestation of massive limb lymphedema, and reviews the relevant literature. We present the following article in accordance with the CARE reporting checklist (available at http:// dx.doi.org/10.21037/tcr-20-3143).

\section{Case presentation}

A 78-year-old female presented a 6-month history of progressive limb edema and accompanied by joint pain over the knees was admitted to our hospital. All procedures performed in studies involving human participants were in accordance with the ethical standards of the institutional and/or national research committee(s) and with the Helsinki Declaration (as revised in 2013). Written informed consent 

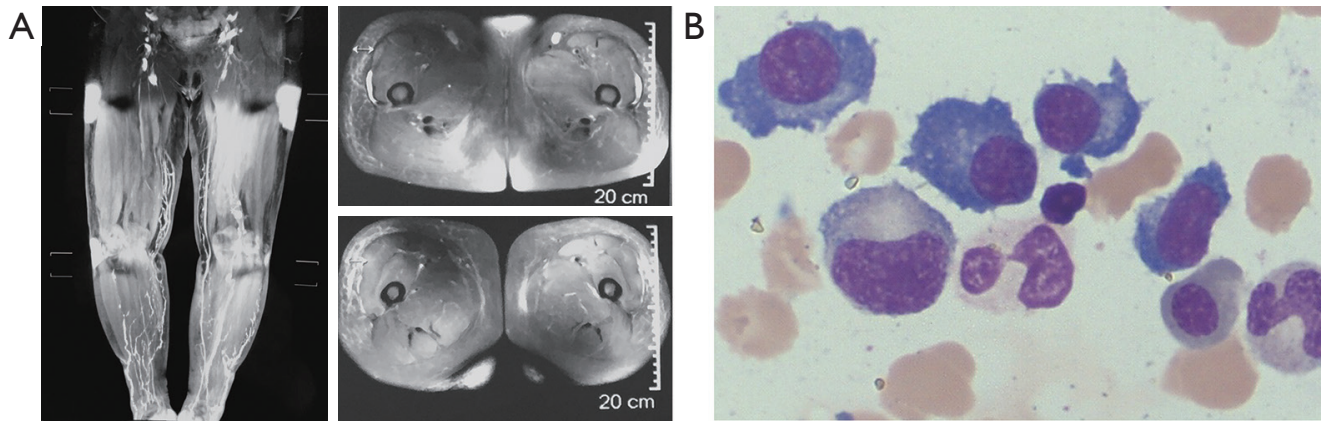

Figure 1 Severe lymphedema as the first manifestation of multiple myeloma. (A) Severe lymphedema in in both legs by Magnetic resonance (MR) lymphangiography. Scale bar: $20 \mathrm{~cm}$. (B) Bone marrow aspiration showing diffuse infiltration of abnormal plasma cells. Bone marrow slices were stained by Wright-Giemsa. Inset is representative magnification image $(1,000 \times)$ of the selected region.

was obtained from the patient.

Physical examination showed massive, firm and nonpitting edema of the arms and legs. Routine blood testing showed mild anemia and normal results for leukocytes and platelets. Blood chemistry results showed concentration of globulin was normal but albumin was at a below normal concentration of $25.5 \mathrm{~g} / \mathrm{L}$ (normal range, $35-55 \mathrm{~g} / \mathrm{L}$ ). Immunoglobulin $\mathrm{G}$ ( $\mathrm{IgG}$ ) level was $2,030 \mathrm{mg} / \mathrm{dL}$ (normal range, $800-1,800 \mathrm{mg} / \mathrm{dL}$ ), while other immunoglobulins were below the normal concentrations. Lambda globulin levels from blood and urine was $1,250 \mathrm{mg} / \mathrm{dL}$ (normal range, $269-638 \mathrm{mg} / \mathrm{dL}$ ) and $222 \mathrm{mg} / \mathrm{dL}$ (normal range, 0 $5 \mathrm{mg} / \mathrm{dL}$ ) respectively. Arteriovenous ultrasound of lower extremities showed no signs of deep vein thrombosis or reflux. Abdominal ultrasound and computed tomography (CT) showed no abdominal or pelvic masses. Magnetic resonance (MR) lymphangiography revealed severe lymphedema in lower extremities and slightly enlarged lymph nodes in groin (Figure $1 A$ ). Serum protein electrophoresis showed a sharp peak in the $\gamma$ fragment, which was identified as $\operatorname{IgG} \lambda$ by immunofixation. The ratio of abnormal plasma cells in the bone marrow accounted for $13 \%$ (Figure 1B). Flow cytometric analysis showed the immunophenotype of abnormal plasma cells was CD38, CD138 and CD56 positive. In addition, 1q21 amplification and deleted in lymphocytic leukemia 1 (13q14) were observed in this patient by fluorescent in situ hybridization (FISH). No evidence of osteolytic lesions was identified on bone emission computed tomography. According to guideline of the International Myeloma Working Group, symptomatic IgG lambda MM (Durie-Salmon stage II and International System Stage II) was diagnosed based on the detected values of an M-protein in the serum, clonal bone marrow plasma cells $>10 \%$ and anemia (hemoglobin $<10$ $\mathrm{g} / \mathrm{dL}$ ). Then the patient was treated with a chemotherapy regimen including bortezomib, cyclophosphamide and dexamethasone (VCD, bortezomib by $1.3 \mathrm{mg} / \mathrm{m}^{2}$ on $\mathrm{d} 1$, 4, 8, 11; cyclophosphamide by $300 \mathrm{mg} / \mathrm{m}^{2}$ on $\mathrm{d} 1,4,8$, 11; dexamethasone by $20 \mathrm{mg}$ on $\mathrm{d} 1-2,4-5,8-9,11-12$ ). After one cycle, IgG recovered to normal level. The concentration of lambda -light from blood was dropped to $913 \mathrm{mg} / \mathrm{dL}$. And the patient's edema started to relieve. After four cycles treatment with VCD, the concentration of lambda-light from blood was dropped to $675 \mathrm{mg} / \mathrm{dL}$ and lymphedema almost completely disappeared. And the patient has no serious toxic effects such as nervous system, diarrhea, intestinal obstruction, and herpes zoster.

\section{Discussion}

Lymphedema was divided into primary and secondary. Secondary lymphedema, caused by an impairment of the lymphatic system due to disease or external trauma (3). In addition to filarial infection, lymphedema secondary to breast cancer is the most common and frequent in the world-wild (4). There is no previous report of multiple myeloma associated with massive lymphoedema. Several studies reported some risk factors in the development of secondary lymphedema. Reported risk factors include history of surgery, trauma, infection, malignant tumors, congenital lymphedema, obesity and traveling to filariasis endemic areas (3). We found no other contributing factors to the patient's massive limb lymphedema except for multiple myeloma. The association between massive limb lymphedema and multiple myeloma was more consolidated, because the patient's lymphedema began to resolve after 
chemotherapy with VCD regimen and almost completely disappeared after 4 months.

Mechanisms of lymphedema were also unclear. Underlying inflammatory mechanisms should be considered as a potential common basis for these risk factors of secondary lymphedema (5). Several trials showed, oral sodium selenite, a nontoxic anti-inflammatory agent with cost-effective that can relieve lymphedema, improve the efficiency of physical therapy, moreover reduce the incidence of erysipelas (6). The inhibition of NF-kappaB (NF- $\kappa \mathrm{B})$ may be one major mechanism for treatment of sodium selenite in lymphedema (7). Many studies also consider the NF- $\kappa \mathrm{B}$ signaling pathway is closely related with the development of lymphedema (8-10). The activation of NF- $\kappa \mathrm{B}$ signaling in multiple myeloma was reported by a wide range of studies (11-13). NF- $\mathrm{BB}$ was active not only in the malignant plasma cell, but also in bone marrow stromal cells (14). NF- $\kappa \mathrm{B}$ is a central signaling pathway that promotes viability of myeloma cell and resistance to apoptosis (15). Bortezomib, a proteasome inhibitor, can inhibit the activity of NF- $\mathrm{\kappa B}$ through blocking the proteasomal degradation of IкB (16). In the case, patient presented with massive lymphedema as the first manifestation of multiple myeloma. After treatment with bortezomib-based chemotherapy, both myeloma and lymphedema began to relieve. All of these results suggested that NF- $\mathrm{KB}$ could make a key contribution to the pathogenesis of lymphedema in this case. This case indicated multiple myeloma may present atypically. We should consider multiple myeloma in the differential diagnosis of massive lymphedema, thereby prompting diagnosis early and treatment precisely.

\section{Acknowledgments}

Funding: This work was supported by a grant from Natural Science Foundation of Zhejiang Province (No. LY20H080006).

\section{Footnote}

Reporting Checklist: The authors have completed the CARE reporting checklist. Available at http://dx.doi. org/10.21037/tcr-20-3143

Conflicts of Interest: All authors have completed the ICMJE uniform disclosure form (available at http://dx.doi. org/10.21037/tcr-20-3143). The authors have no conflicts of interest to declare.
Ethical Statement: The authors are accountable for all aspects of the work in ensuring that questions related to the accuracy or integrity of any part of the work are appropriately investigated and resolved. All procedures performed in studies involving human participants were in accordance with the ethical standards of the institutional and/or national research committee(s) and with the Helsinki Declaration (as revised in 2013). Written informed consent was obtained from the patient.

Open Access Statement: This is an Open Access article distributed in accordance with the Creative Commons Attribution-NonCommercial-NoDerivs 4.0 International License (CC BY-NC-ND 4.0), which permits the noncommercial replication and distribution of the article with the strict proviso that no changes or edits are made and the original work is properly cited (including links to both the formal publication through the relevant DOI and the license). See: https://creativecommons.org/licenses/by-nc-nd/4.0/.

\section{References}

1. Naymagon L, Abdul-Hay M. Novel agents in the treatment of multiple myeloma: a review about the future. J Hematol Oncol 2016;9:52.

2. Mortimer PS. The pathophysiology of lymphedema. Cancer 1998;83:2798-802.

3. Warren AG, Brorson H, Borud LJ, Slavin SA. Lymphedema: a comprehensive review. Ann Plast Surg 2007;59:464-72.

4. Williams AF, Franks PJ, Moffatt CJ. Lymphoedema: estimating the size of the problem. Palliat Med 2005;19:300-13.

5. Ridner SH. Pathophysiology of lymphedema. Semin Oncol Nurs 2013;29:4-11.

6. Micke O, Schomburg L, Buentzel J, et al. Selenium in oncology: from chemistry to clinics. Molecules 2009;14:3975-88.

7. Pfister C, Dawzcynski H, Schingale FJ. Sodium selenite and cancer related lymphedema: Biological and pharmacological effects. J Trace Elem Med Biol 2016;37:111-6.

8. Smahi A, Courtois G, Rabia SH, et al. The NF-kappaB signalling pathway in human diseases: from incontinentia pigmenti to ectodermal dysplasias and immune-deficiency syndromes. Hum Mol Genet 2002;11:2371-5.

9. Aradhya S, Nelson DL. NF-kappaB signaling and human 
disease. Curr Opin Genet Dev 2001;11:300-6.

10. Leung G, Baggott C, West C, et al. Cytokine candidate genes predict the development of secondary lymphedema following breast cancer surgery. Lymphat Res Biol 2014;12:10-22.

11. Demchenko YN, Glebov OK, Zingone A, et al. Classical and/or alternative NF-kappaB pathway activation in multiple myeloma. Blood 2010;115:3541-52.

12. Landowski TH, Olashaw NE, Agrawal D, et al. Cell adhesion-mediated drug resistance (CAM-DR) is associated with activation of NF-kappa B (RelB/p50) in myeloma cells. Oncogene 2003;22:2417-21.

Cite this article as: Yang C, You L, Meng H. Massive limb lymphedema as the initial presentation of multiple myeloma: a case report. Transl Cancer Res 2021;10(3):1599-1602. doi: $10.21037 /$ tcr-20-3143
13. Keats JJ, Fonseca R, Chesi M, et al. Promiscuous mutations activate the noncanonical NF-kappaB pathway in multiple myeloma. Cancer Cell 2007;12:131-44.

14. Matthews GM, de Matos Simoes R, Dhimolea E, et al. $\mathrm{NF}-\kappa \mathrm{B}$ dysregulation in multiple myeloma. Semin Cancer Biol 2016;39:68-76.

15. $\mathrm{Hu} \mathrm{J}, \mathrm{Hu}$ WX. Targeting signaling pathways in multiple myeloma: Pathogenesis and implication for treatments. Cancer Lett 2018;414:214-21.

16. Vrábel D, Pour L, Ševčíková S. The impact of NF-кB signaling on pathogenesis and current treatment strategies in multiple myeloma. Blood Rev 2019;34:56-66. 